\title{
A commemoration of my mentor, Professor Thomas Patrick Joseph Hennessy
}

\author{
Hui Li \\ Department of Thoracic Surgery, Beijing Chao-Yang Hospital, Capital Medical University, Beijing 100020, China \\ Correspondence to: Hui Li. Department of Thoracic Surgery, Beijing Chao-Yang Hospital, Capital Medical University, Beijing 100020, China. \\ Email: huilee@vip.sina.com.
}

Submitted May 08, 2018. Accepted for publication May 09, 2018.

doi: $10.21037 /$ jtd.2018.05.84

View this article at: http://dx.doi.org/10.21037/jtd.2018.05.84

On the evening of April 14, 2018, I received an unexpected email from Mrs. Birgitta Hennessy, the wife of my mentor, Professor TPJ Hennessy. A tinge of uneasiness crossed my mind and my heart sank when I read the email: "Dear Huilee, it is with great sorrow that I am informing you that my dear husband, Tom Hennessy, died last Monday after a short illness (heart failure)." Sadness struck me hard for the remainder of the night. Scenes of my three years of studying in Dublin flashed back and forth before my eyes while the voice and smile of Prof. Hennessy lingered in my mind. I posted a short passage with a few commemorative photographs on WeChat Moment to express my condolences. Later that night, Mr. Daoyuan Wang, the CEO of AME Publishing Company, sent me a text asking me to write an article for their $7 T D$ journal in commemoration of Prof. Hennessy's lasting contribution to thoracic surgery.

I first became acquainted with Prof. Hennessy through the mail. Back in 1988, following the trend of studying abroad, I applied for a researcher position in Prof. Hennessy's lab. I wrote him a letter on September 3. I did not actually know him before I wrote to him, but I learned of his name through his published works. A few weeks later, I received a response from him accepting me as his student (Figures 1,2).

During the following year, I spent most of my free time studying English at Beijing Foreign Studies University while simultaneously applying for my passport and visa. Thanks to Prof. Hennessy's personal involvement, I received my visa for studying in Ireland without any problems.

In August 1989, I boarded a plane to Ireland and began my 3 years of studying abroad. My first journey to Dublin was not a smooth one. At that time, I was not aware that there were two international airports in London. I flew from Beijing to Heathrow Airport, but then I was told that the connecting flight from London to Dublin was in Gatwick Airport! One could imagine how confused I was when I learnt this. Communication was not easy at that time since there were no cell phones, so I used a pay phone at the airport to inform Prof. Hennessey that I would not arrive on time. When I finally arrived at Dublin and walked out of the terminal, I heard a voice saying, "You must be Dr. Li." I turned around and saw a very amiable gentleman smiling and greeting me. "You must be Prof. Hennessy" I eagerly replied with great relief. Then, we shook hands and started chatting like old friends. I asked him how he could recognize me among all the passengers. With a hint of humor, he told me that he could tell from my face. Back then, only a few Chinese went abroad. If the same situation were to happen today, it would be nearly impossible for him to identify me so easily. After a brief chat, he drove me to my dormitory in Dublin, and I settled in without any trouble. On the way to the dormitory, he brought me to a church. He told me that his wedding was held there and he attended this church every weekend. This was the first time I walked into a sacred church. Actually, I went to that church many times during the three years that I was in Ireland. I prayed there whenever something made me happy or troubled even though I am not Catholic. The first place I stayed was in a nurses' dormitory, which was arranged for me in advance by Prof. Hennessey. It was a cozy single suite with moderate monthly rent. It was a great help for me to have a nice place 


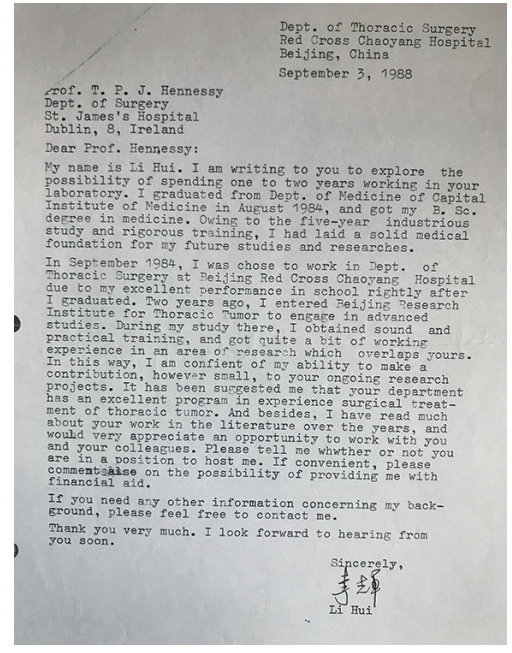

Figure $1 \mathrm{My}$ application letter to study abroad. to stay on my first day thousands miles away from home.

Prof. Hennessy was Regius Professor of Surgery and the Head of the Department of Surgery at Trinity College Dublin. He had full schedule every day. In addition to working in the Head of clinic, doing ward rounds, and performing surgery, he also participated in many academic events and wrote books. Fortunately, he had two secretaries; one was in charge of academic work and the other was in charge of clinical work. He worked in a unique way-he dictated records for clinic patients and surgery, as well as for his articles and books, then his secretaries transcribed them into text. Prof. Hennessy was an internationally renowned esophageal surgeon, particularly in gastroesophageal reflux disease. He published many textbooks. One of his books, Esophageal Surgery, was translated into Chinese by Prof.

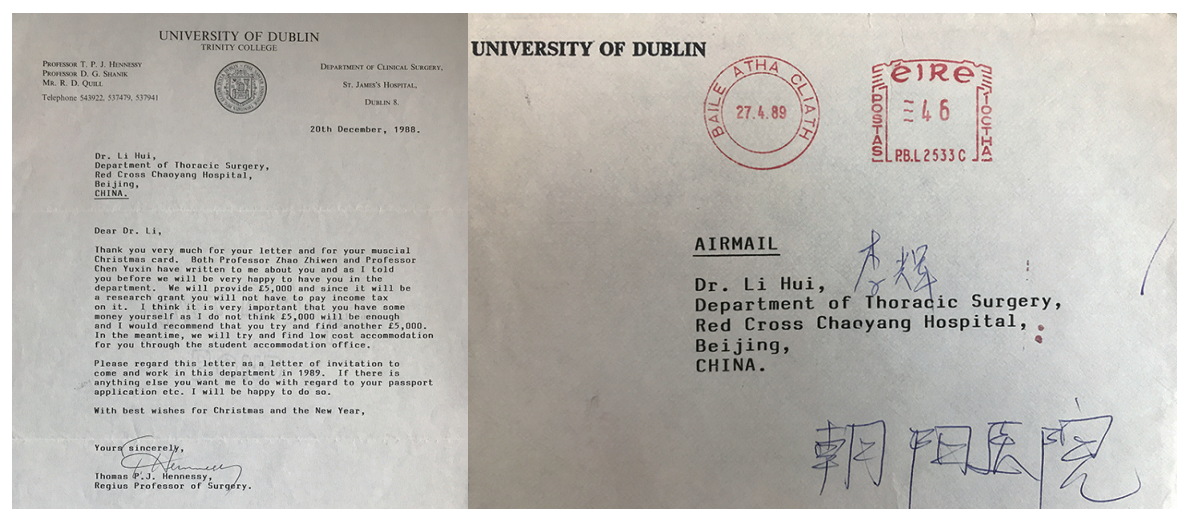

Figure 2 An acceptance letter of Prof. Hennessy.

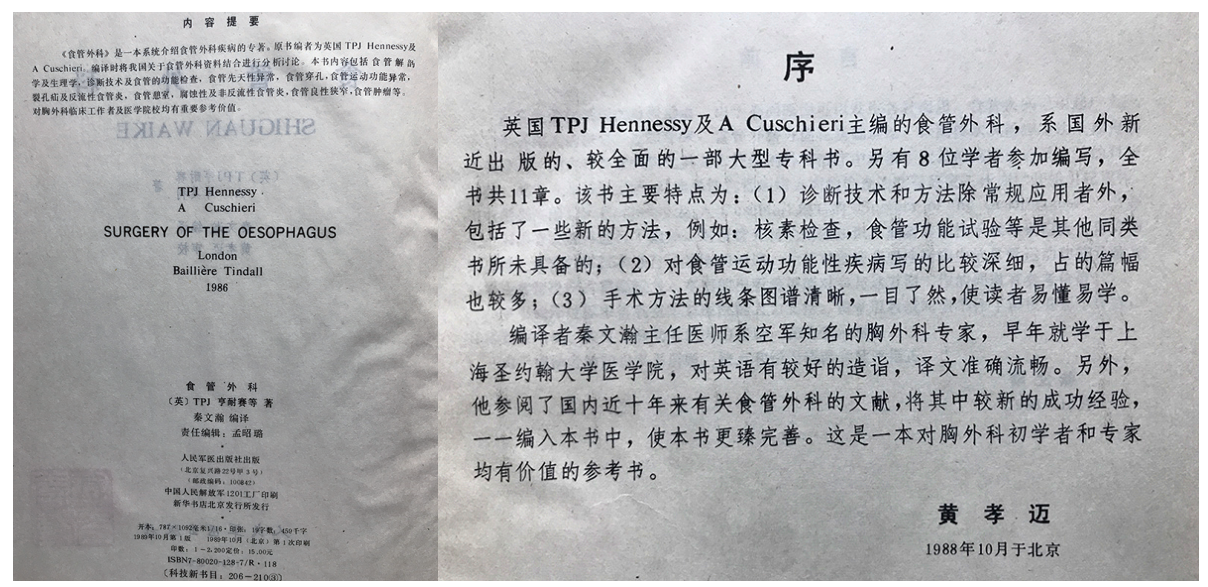

Figure 3 The Chinese translation of Esophageal Surgery and the preface by Professor Xiaomai Huang. 


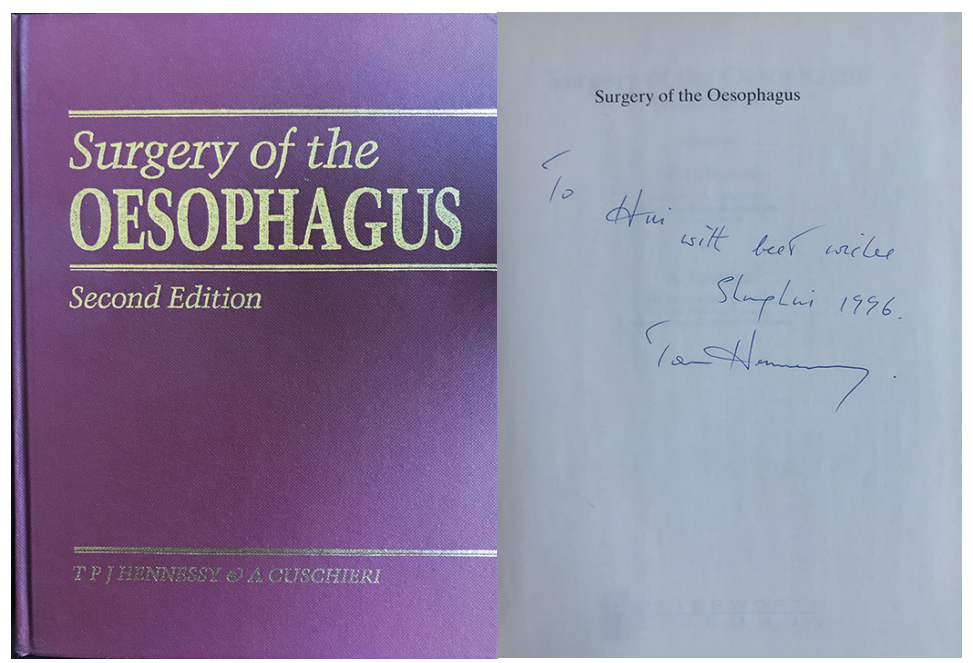

Figure 4 The original version of Surgery and the professor's signature page.

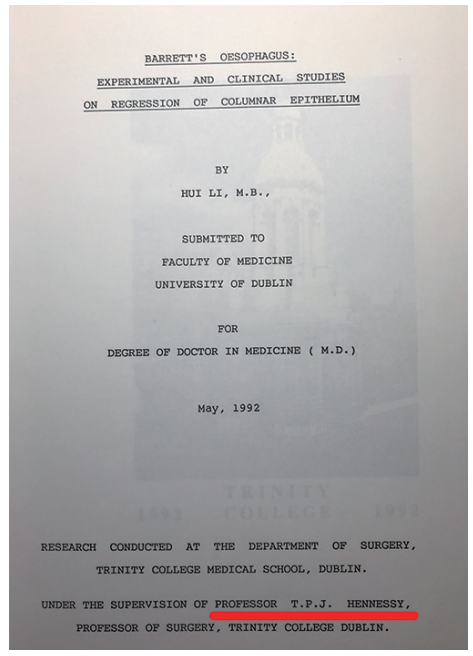

Figure 5 Title page of the dissertation.

Wenhan Qin of Air Force General Hospital in 1989, and Prof. Xiaomai Huang wrote the preface (Figures 3,4). Prof. Hennessy also published numerous articles; the most famous one that is frequently cited was published in 1996 in the New England Fournal of Medicine about neoadjuvant chemotherapy for esophageal cancer.

As I set up and designed my own research topic, he devoted a great deal of effort. Under his guidance and with help from his assistant, Mr. Tom Walsh, I completed the animal study of my research and my doctoral dissertation, passing dissertation defense in June 1992 (Figure 5). Research articles based on my doctoral dissertation were published in Surgery and Surgery, Gynecology \& Obstetrics (Figure 6). During my three years of studying in Ireland, Prof. Hennessy arranged for me to make academic presentations at international conferences. My first presentation was at the Royal College of Surgeons (Ireland), and the others were at the Annual meeting of Surgical Research Society (Liverpool, UK).

At that time, the topic I was working on was mucosal metaplasia of Barrett's esophagus. It was believed that Barrett's esophagus was a type of precancerous pathology. If anti-reflux treatment can reverse the mucous membrane, then the approach may be used to prevent cancer. This was our theoretic hypothesis and we devised an animal experiment, which was hard to conduct. I clearly remember that we had to induce severe gastroesophageal reflux in canine model, and then perform anti-reflux repair surgery to observe the changes in the mucous membrane. In this process, animals may present certain serious symptoms and become unwilling to eat. In order to ensure the survival of the experiment animals, I once fried sausages over Christmas and fed the animals. In the meantime, we also had to do esophageal $\mathrm{pH}$ testing on the animals, so we had to spend several hours sitting with the animals to ensure that the $\mathrm{pH}$ test catheter did not fall out.

In addition to scientific research, I also conducted some clinical work. At first, I just observed surgery. Later on, due to my excellent performance in animal experimental surgery, Prof. Hennessy allowed me to serve as his assistant in surgery. In doing so, he set a precedent in European countries, which are very strict about medical practice 


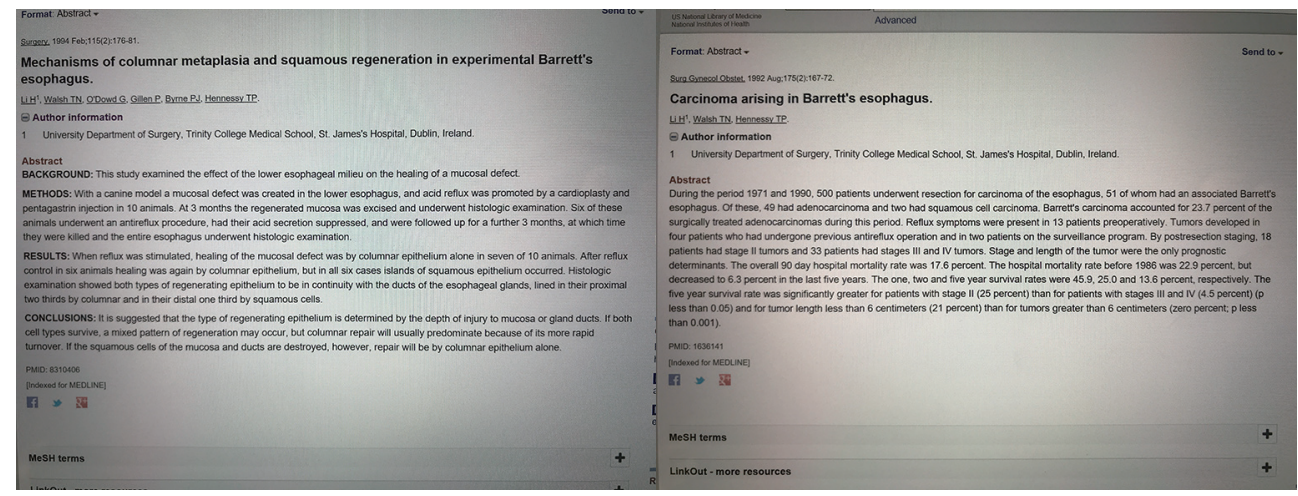

Figure 6 My early SCI publications.

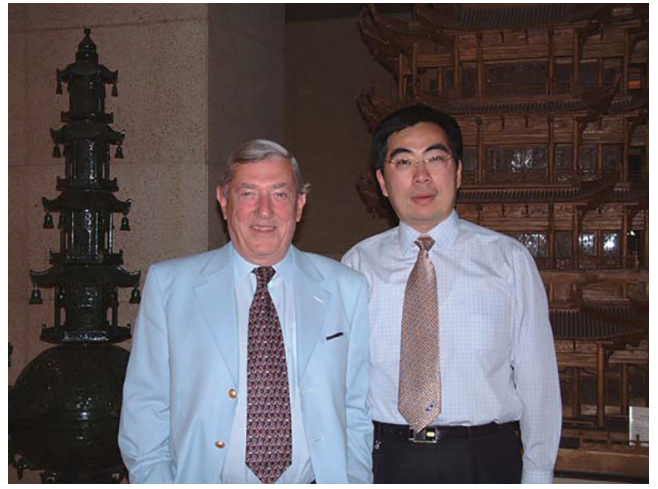

Figure 7 Photo taken with the professor in 1992.

licenses. I have two funny stories about my professor and surgery. The first time I was in an operating room, the professor asked me, "Would you like to go to the theater with me?" I thought he meant a movie theater and it was very strange that he was asking me to see a movie before surgery. The other story involved a two-incision esophageal surgery, which was already very popular in Europe by 1989 , but I had not seen one at the time. When the surgeons finished with the abdominal part, they closed the incision and everyone took off their scrubs and started drinking coffee in the lounge. I was totally confused and wondered why this simple surgery was an exploratory one. Without drinking any coffee, I went back to my office. Half an hour later, the operating room called me and said that the surgery was restarting. That was the first time I learned that esophageal surgery could be done in two steps. In the latest expert consensus for China, entry on the right side of the chest was recommended; but in fact, many Chinese thoracic surgeons are still accustomed with entry on the left side.
In the continuing education system for medicine in the UK and Ireland, there are two types of degrees after graduation. The first is called an "academic degree," while the other is called a "professional degree." A Board Examination of the Royal College of Surgeons is a professional degree, which can be used to engage in clinical practice. People usually obtain professional degrees first and then study for an academic degree, such as $\mathrm{MD}$ or $\mathrm{PhD}$, if they have the opportunity. However, an academic degree alone cannot be used to practice medicine. Before I went to Ireland, Prof. Hennessy did not have a doctorate degree. After I applied for the doctoral program, he also applied for a doctoral degree. Perhaps he felt a little embarrassed that his student had a doctoral degree, but he did not.

Prof. Hennessy also had many good friends in the field of surgery, including Prof. Cuschieri in the United Kingdom. Prof. Cuschieri was one of the pioneers to apply a thoracoscope to esophageal surgery. His pioneering work is the most cited paper and we all benefited immensely from it. He was also a coauthor with Prof. Hennessy for Esophageal Surgery, and Prof. Hennessy asked him to be one of the reviewers of my dissertation.

Prof. Hennessy not only cared for my professional needs, but he also cared about my personal life. I lost some weight after I arrived in Ireland as I was not used to the new diet. One day, Prof. Hennessy suddenly asked me, "Did you lose some weight?" Several months after I arrived in Ireland, my son was born. A few days around the due date, I was quite anxious, and the professor told me, "No news is good news." The first Christmas when I was in Ireland, he invited me to his home for Christmas dinner.

After completing my dissertation defense in 1992, I returned to Beijing to continue my clinical and research work. In 1994, Prof. Hennessy paid his first visit to Beijing 


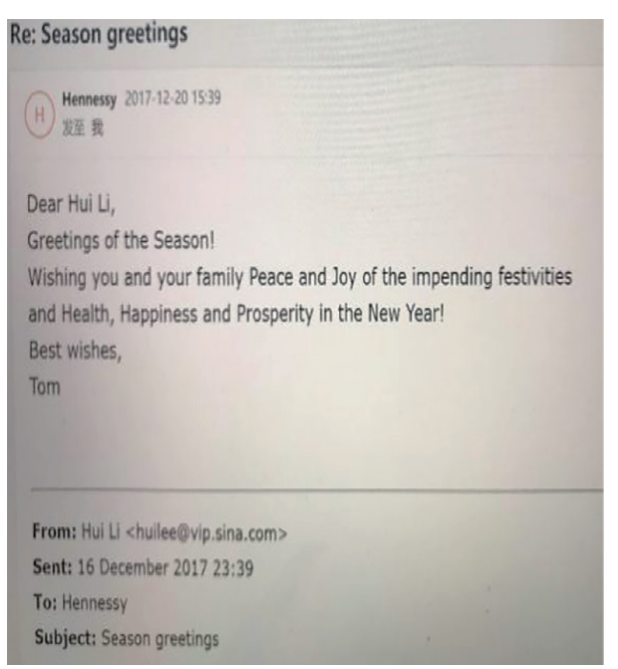

Figure 8 Last email from Prof. Hennessy.

《收件箱
Birgitta Buckholt-Hennessy $17: 24$
发至我 详情
Dear Huilee,
It is with great sorrow I am informing you that my
dear husband Tom Hennessy
died last Monday after a short illness
(heartfailure).
He was very proud of you and considered you a
brilliand doctor and surgeon.
Kind regards,
Birgitta Hennessy

Figure 9 An email from Prof. Hennessy' wife.

(Figure 7). I took him to Kempinski Hotel Beijing twice and we chatted a lot. He told me that we spoke more over the past two days in Beijing than during the three years I spent in Ireland. At the time, he was the President of the
Royal College of Surgeons (Ireland). After that, we did not see each other again; however, we continued to exchange Christmas greetings each year until December 2017, which was the last time we were in contact (Figure 8).

After I returned to China in 1992, I devoted my efforts to benign esophageal diseases for a considerable amount of time. In particular, I worked on promoting issues relating to functional esophageal diseases. Although pulmonary surgery has been my key focus at work since I arrived at Chaoyang Hospital in 2004, it has not lessened my passion for esophageal surgery. In recent years, I also presided over drafting the consensus among Chinese experts regarding chest lymphadenectomy for esophageal cancer, which has an important effect on promoting the standardization of esophageal surgery in China.

In her email to me, Prof. Hennessy's wife said: "He was very proud of you and considered you a brilliant doctor and surgeon." I am extremely grateful to Prof. Hennessey for his approval and encouragement. His words will continue to drive me forward (Figure 9).

May Prof. Hennessy rest in peace and God bless him.

\section{Acknowledgements}

I would like to thank my brother, Mr. Lin $\mathrm{Li}$, for his invaluable support in editing this manuscript.

\section{Footnote}

Conflicts of Interest: The author has no conflicts of interest to declare.

Cite this article as: $\mathrm{Li} \mathrm{H}$. A commemoration of my mentor, Professor Thomas Patrick Joseph Hennessy. J Thorac Dis 2018;10(5):2537-2541. doi: 10.21037/jtd.2018.05.84 